\title{
P142 Androgen Receptor Reduced Sensitivity is Associated with Cardiovascular Mortality in Men with Type 2 Diabetes - A 14-year Follow up Study
}

\author{
Adrian Heald ${ }^{1,2,}$, Ghasem Yadegarfar ${ }^{2,3}$, Mark Livingston ${ }^{4}$, Helene Fachim $^{1,2}$, Ram Prakash Narayanan ${ }^{2,5}$, \\ Mark Lunt ${ }^{6}$, Kirk Siddals ${ }^{6}$, Gabriela Cortes ${ }^{7}$, Martin Gibson ${ }^{1,2}$, Rachelle Donn ${ }^{2}$, Simon Anderson ${ }^{8}$, \\ Geoff Hackett ${ }^{9}$, Hugh Jones ${ }^{10}$ \\ ${ }^{1}$ Salford Royal Hospital, Salford, UK \\ ${ }^{2}$ University of Manchester, UK \\ ${ }^{3}$ Isfahan University of Medical Sciences, Isfahan, Iran \\ ${ }^{4}$ Walsall Manor Hospital, Walsall, UK \\ ${ }^{5}$ University of Liverpool, UK \\ ${ }^{6}$ University of Manchester \\ ${ }^{7}$ High Speciality Regional Hospital of Ixtapaluca, Mexico City, Mexico \\ ${ }^{8}$ University of the West Indies, Barbados \\ ${ }^{9}$ Heartlands Hospital, Birmingham, UK \\ ${ }^{10}$ University of Sheffield, Sheffield, UK
}

\section{ABSTRACT}

Background: Hypogonadism associates with increased cardiovascular morbidity/mortality in type 2 diabetes mellitus (T2DM) [1]. Increasing CAG repeat number within exon 1 of the androgen receptor gene associates with increased androgen receptor resistance/insulin resistance [2]. We here investigated the link between CAG repeat number and metabolic/cardiovascular outcomes in T2DM men.

Methods: We determined in a 14-year follow-up cohort of 274 T2DM Caucasian men in Salford UK, the association between baseline androgen status/CAG repeat number (determined by PCR followed by Sequenom sequencing) and metabolic trajectory plus mortality.

Results: Lower baseline testosterone was associated with higher Body Mass Index (BMI) $\left(\mathrm{kg} / \mathrm{m}^{2}\right)$ at 14-year follow-up: regression coefficient -0.30 ( $95 \%$ CI: -0.445 to -0.157 ), $p=0.0001$ (total testosterone data) and higher HbAlc 2016. Higher baseline CAG repeat number associated with higher follow-up BMI in 2016 - each unit increase in CAG repeat associated with 0.43 increment in BMI 2016. At an average 14 year follow-up $55.8 \%$ of hypogonadal men had died vs $36.1 \%$ of eugonadal men $(p=0.001) .72 \%$ of deaths were from cardiovascular causes. There was a 'u' shaped relation between the number of CAG repeats and mortality such that 21-23 CAG repeats was associated with an up to $58 \%$ lower mortality rate than $<21$ CAG repeats and $>23$ CAG repeats (Figure 1). This was independent of baseline testosterone.

Conclusion: A higher number of CAG repeats at the testosterone receptor gene associates with higher future BMI/increased $\mathrm{HbAlc}$. There was a ' $\mathrm{u}$ ' shaped relation between CAG repeat number and mortality rate. CAG repeat number may become part of cardiovascular risk assessment in T2DM men.

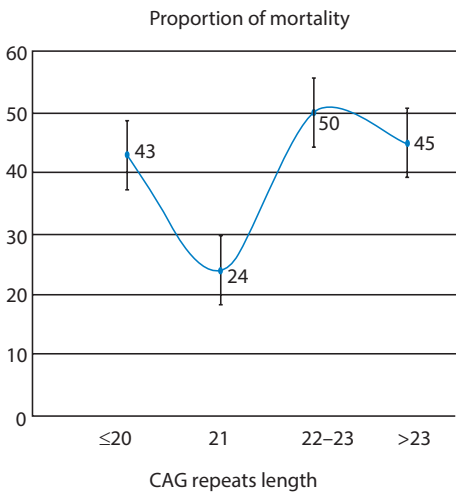

Figure 1 


\begin{tabular}{lcccc}
\hline CAG_cat & Mortality & $\begin{array}{c}\text { Proportional } \\
\text { mortality rate }\end{array}$ & $\begin{array}{c}\text { Lower } \\
\text { bound }\end{array}$ & $\begin{array}{c}\text { Upper } \\
\text { bound }\end{array}$ \\
\hline$\leq 20$ & 40 & 43 & 32 & 53 \\
21 & 12 & 24 & 13 & 39 \\
$22-23$ & 28 & 50 & 36 & 64 \\
$>23$ & 34 & 45 & 34 & 57 \\
\hline
\end{tabular}

\section{REFERENCES}

[1] Muraleedharan V, Marsh H, Kapoor D, Channer KS, Jones TH. Testosterone deficiency is associated with increased risk of mortality and testosterone replacement improves survival in men with type 2 diabetes. Eur J Endocrinol 2013;169:725-33.

[2] Stanworth RD, Kapoor D, Channer KS, Jones TH. Androgen receptor CAG repeat polymorphism is associated with serum testosterone levels, obesity and serum leptin in men with type 2 diabetes. Eur J Endocrinol 2008;159:739-46.

(C) 2019 Association for Research into Arterial Structure and Physiology. Publishing services by Atlantis Press International B.V. This is an open access article distributed under the CC BY-NC 4.0 license (http://creativecommons.org/licenses/by-nc/4.0/). 